\title{
Fotografi Ruang Siber dan Layar Panoptik Analisis Foto dalam Media Sosial Instagram
}

\author{
Daru Tunggul Aji \\ Program Studi Desain Komunikasi Visual \\ Fakultas Seni Rupa ISI Yogyakarta \\ daruaji19@gmail.com
}

\begin{abstract}
This paper discusses a photography phenomenon materialized in a social media, the Instagram. Within a social media, like Instagram, photography is used to establish a power relation and is the representation of the user. Photography is no longer a media for documentation; recently it is a display of a symbol of modern life style. Media social users set up their identity as they wish. In this political space (a space full of interests), each user seeks to strategize power, to oversee and discipline one another. To scrutinize this matter Michel Foucault's panopticon concept is employed. This study aims at explaining the phenomenon of the Amaryllis garden destruction happened in Patuk District, Gunungkidul Regency, Yogyakarta Special Region Province. The features provided by Instagram to respond the posted photograph such as "like", "comment", "share", and hashtag (\#) are unconsciously used by the users to play the overseer role. The panoptic tower functions and is strategized to keep watch and discipline other users.
\end{abstract}

Keywords: Photography, Lifestyles, Social Media, Instagram, Panopticon.

Relevance to Visual Communication Design Practise: As a visual-based social media, instagram becomes an interactive space that utilizes the power of visual in responding various phenomena. One among the others is by using photography as an integral part of visual communication design

\section{RILISNYA FOTOGRAFI DAN GAYA HIDUP MODERN}

Memasuki tahun 1839, fotografi mulai banyak diperbincangkan di Eropa, terlebih lagi ketika Daguerretype mulai rilis dan mulai digunakan sebagai medium rekam yang dianggap mampu memberikan citraan mirip dengan kondisi yang sebenarnya. Adalah Louis J.M. Daguerre (1787-1851) yang mengenalkan hasil eksperimennya tersebut pada suatu pertemuan ilmiah di Paris tanggal 19 Agustus 1839, meski Daguerre tidak hadir dalam pertemuan itu, namun presentasi hasil karyanya diwakilkan kepada Francois Arago (1786-1853), seorang ilmuwan yang juga adalah anggota parlemen Perancis. Karya Daguerre dihargai pemerintah Perancis, dan sejak saat itu karya tersebut diyakini sebagai titik tolak penemuan fotografi kimiawi (Setiawan dan Mardohar, 2015: 15).

Selanjutnya Daguerretype mulai banyak dikenal dan digunakan dalam pendokumentasian berbagai hal. Seperti yang dilakukan oleh seorang pegawai kesehatan Belanda, Jurrian Munich. Pada 1841, Ia melakukan kunjungan ke wilayah Jawa Tengah untuk melakukan pendokumentasian pemandangan alam dan tanaman. Sayangnya dari 64 gambar hasilnya sangat mengecewakan. Kegagalannya lebih bersifat teknis dan kelembaban udara tropis yang luput dari perhitungannya. (Sunjayadi, 2008).

Kelemahan-kelemahan pada Daguerreotype terus diperbaiki. Inovasiinovasi terus dilakaukan oleh beberapa Ahli. 
Hingga pada tahun 1850-an, fotografi mengalami perkembangan cepat dengan dikenalnya Prosede Kolodion. Prosede itu memungkinkan untuk membuat beberapa afdruk (cetakan) dari satu negatif kaca (Sunjayadi, 2008). Selanjutnya pada tahun 1844 seorang berkebangsaan Inggirs bernama William Fox Talbot melakukan eksperimen dan menemukan teknik mencetak gambar yang bisa diperbanyak dengan menggunakan film negatif, kemudian teknik ini dikenal dengan Calotype.

Melalui inovasi-inovasi yang dilakukan dalam fotografi, pendokumentasian semakin mudah dilakukan. Citraan bisa dikopi berkali-kali lipat. Perangkat kamera menjelma sebagai pertanda kehidupan modern. Dalam pengantarnya, Strassler (2010) bertutur tentang bagaimana Minke -tokoh dalam Tetralogi Pulau Buru karangan Pramodeya Ananta Toer- "merenungkan" fotografi. Baginya, fotografi telah menjadi perlambang kehebatan jaman modern, mampu memupus ruang dan waktu, seolah-olah dunia tak lagi berjarak, dan mampu melampaui batas geografis maupun sosio-kultural. Pendeknya, dalam jaman modern ini potret sudah dapat diperbanyak sampai puluhan ribu sehari, tulis Pram dalam Bumi Manusia.

Bisa dikatakan, bahwa fotografi menjadi perangkat yang cukup canggih pada waktu itu. Lahirnya fotografi turut mewarni perkembangan teknologi komunikasi (visual). Dalam buku Technological Determinism, Mc Luhan membagi periodisasi perkembangan komunikasi menjadi embat bagian, yaitu Tribal Age, Literature Age, Print Age, dan Electronic Age. Pada periode ketiga, Print Age, memberikan dampak kemajuan dan dorongan manusia untuk memproduksi sekaligus menggandakan tulisan, selain itu juga berdampak pada unsur-unsur visual fotografis. Imaji yang terekam mampu diperbanyak hingga puluhan, bahkan ribuan kali. Terlebih lagi ketika memasuki periode Electronical Age, dimana teknologi komunikasi ditandai dengan munculnya komunikasi melalui kabel, bahkan nirkabel yang menjadi cikal bakal lahirnya ruang siber (cyberspace).

Fotografi lahir dalam situasi sosial politis yang belum stabil akibat revolusi industri di Eropa. Banyak pabrik baru muncul, sementara perdagangan berkembang semakin pesat. Struktur sosial mengalami perubahan dengan munculnya kelas menengah, yang memiliki kesadaran intelektual dan kebebasan tinggi. Sains dan teknologi berkembang semakin canggih, didukung oleh pemerintah yang menerapkan kebijakan untuk meningkatkan kemajuan ekonomi lewat perdagangan dan industri. (Setiawan dan Mardohar, 2015: 15). Inovasi dalam perangkat kamera, dari kamera film ke kamera digital membawa perubahan yang cukup penting bagi kehidupan masyarakat. Memotret bukan hanya domain kerja-kerja jurnalistik dan kerja-kerja periklanan yang dikerjakan oleh fotografer profesional. Fotografi menjadi sesuatu yang lumrah kita temui dan menjadi perlambang penggambaran- gaya hidup modern. Siapapun mampu mengidentifikasikan dirinya sebagai masyarakat modern, melalui kamera dan kemampuan mengada di hadapan lensa. Melalui kerja-kerja fotografis, kunjungan ke sebuah wilayah menjadi lebih politis (penuh kepentingan). Memotret dan dipotret bukan lagi kerja-kerja dokumentasi, 
lebih jauh ia menjadi proyek diri sebagai manusia modern.

Pendapat Chaney, dalam Lifestyles (1996) seperti dikutip oleh Ibrahim (2011: 306-307) sebagai konsep dalam kajian budaya dan media, istilah gaya hidup telah dimaknai sebagai konsep yang kompleks. Sebagai satu bentuk pembedaan sosial, gaya hidup dimaknai dengan cara berbeda-beda, sehingga tak heran kalau gaya hidup menjadi "sumber penafsiran" yang terbuka. Pun dalam konteks yang visual (baca: fotografi) sejak kemunculannya fotografi mengindikasikan hadirnya "pembedaan kelas". Fotografer memiliki kuasa atas kamera serta memiliki kuasa untuk mengkonstruksikan realitas, pun bagi objek foto, ketika ia termediakan melalui kamera maka secara sadar ia telah menempatkan dirinya dalam posisi tertentu. Melalui pose, dandanan, serta tempat ia berpose memberikan posisi tawar akan keberadaan dirinya.

Karen Strassler dalam Refracted Visions: Popular Photography and National Modernity in Java seperti dikutip oleh Seno Gumira Ajidarma (2016: 113) mengungkapkan bawa semenjak sejarah kelahiran studio foto di Hindia Belanda dan kemudian Indonesia, berlangsung perubahan yang maknanya penting dalam arti ideologis. Pada waktu itu muncul studio foto orang Tionghoa, Eropa, juga Jawa. Mereka yang pergi ke studio orang eropa, selain masyarakat eropa dan indo adalah elit pribumi.

Di antara tiga studio foto saling berstrataegi dalam menarik calon konsumen, melalui gambar-latar yang penuh dengan citra dunia yang modern. Atribut-atribut dalam studio foto menyimbolkan ikon-ikon masyarakat modern. Pose bersama televisi, sepeda, atau bahkan kamera. Fotografi mampu menjadi medium bagi objek foto untuk "eksis", "berada" dan membangun imaji atas dirinya. Identifikasi diri yang modern, yang bergaya, serta mampu berada dalam strata tertentu. Dari hal ini terlihat bagaimana citraan visual pada fotografi mampu membangun imaji mengenai kelas sosial juga menyoal perihal keberadaan.

$$
\text { Yasraf Amir Pilliang, }
$$
mengungkapkan bahwa ada hubungan timbal balik dan tidak dapat dipisahkan antara keberadaan citra (image) dan gaya hidup (lifestyle). Gaya hidup sebagai cara manusia memberikan makna pada dunia kehidupannya, membutuhkan medium dan ruang untuk mengekspresikan makna tersebut, yaitu ruang bahasa dan benda-benda yang di dalamnya citra mempunya peran yang sangat sentral. Dalam gaya hidup yang dijembatani oleh fotografi seseorang membangun identitas diri dan kelompoknya, seperti dapat kita saksikan dalam foto-foto perjalanan, misalnya foto wisata yang kerap muncul di sosial media. Keterhubungan antara sosial media dengan foto-foto perjalanan ini menarik. Sosial media menjadi ruang yang kompleks dan begitu cair jika menyoal posisi identitas diri..

Sejak kemunculan cyberspace (selanjutnya saya sebut Ruang Siber), ruang yang diperantarai oleh kabel atau bahkan nirkabel telah membuat ruang kehidupan masyarakat makin rapat. Awalnya konsep ruang siber dikenalkan oleh penulis William Gibson melalui novel sci-fic Neuromancer (1984). Gibson mengenalkan konsep ini untuk menggambarkan sebuah ruang/tempat yang virtual namun keberadaanya dapat dirasakan, bahkan "terasa" begitu dekat dan 
nyata dalam benak seseorang. Penggambaran ini muncul setelah Gibson mengamati fenomena anak-anak ketika bermain Video Game. Barker (2009:329) menerangkan konsep cyberspace dimana email berlalu lalang, transfer uang elektronik berlangsung, pesan-pesan digital bergerak dan situs-situs World-Wide-Web diakses. 'suatu "tempat tanpa ruang" secara konseptual, dimana katakata, hubungan antarmanusia, data, status kekayaan dan kekuasaan dimunculkan oleh orang-orang yang menggunakan teknologi komunikasi dengan perantara computer' (Ogden, 1994: 715). Dengan kemunculan teknologi komputer mampu mengubah polapola komunikasi antar penggunanya. Terutama dapat kita lihat dalam fenomena media siber. Tanpa perlu bertatap muka, tanpa terkendala jarak, ruang, dan waktu. Bukan hanya membangun dialog, namun dalam kondisi tertentu, media dalam ruang siber mampu membangun forum-forum obrolan yang melibatkan banyak pengguna. Fasilitas kolom komentar mampu menjadi fasilitator. Siapa saja bisa ikut berkomentar, bahkan tanpa harus saling mengenal satu sama lain.

Ada banyak ragam jenis-jenis media siber. Rulli Nasrullah dalam Teori dan Riset Media Siber (2014: 36-37) membagi jenisjenis media siber, di antaranya: Situs ( Web Site), Email, forum di internet (Bulletin Boards), Blog, Wiki, Aplikasi Pesan, Internet Broadcasting, The RSS, Muds, dan Media Sosial. Kehadiran media sosial seperti Facebook, Twitter, dan Instagram merupakan media yang digunakan untuk memublikasikan konten seperti profil, aktivitas, atau bahkan pendapat pengguna juga sebagai media yang memberikan ruang bagi komunikasi dan interaksi dalam jejaring sosial di ruang siber.

Di antara media sosial yang sudah disebutkan sebelumnya, pembahasan akan berfokus pada media sosial Instagram. Dengan salah satu pertimbangannya, Instagram merupakan media sosial yang memang diperuntukkan berbagi foto. Media sosial menurut Van Dijk (2013) dalam Nasrullah (2015:11) menyatakakan bawa media sosial adalah platform media yang memfokuskan pada eksistensi pengguna yang memfasilitasi mereka dalam beraktivitas maupun berkolaborasi. Karena itu, media sosial dapat dilihat sebagai medium (fasilitator) online yang menguatkan hubungan antar pengguna sekaligus sebuah ikatan sosial.

Dikutip dari laman www.netterku.com, nama Instagram berasal dari pengertian dari keseluruhan fungsi aplikasi ini. Kata "Insta" berasal dari kata "Instan", seperti kamera polaroid yang pada masanya lebih dikenal dengan sebutan "Foto Instan". Instagram juga dapat menampilkan foto-foto secara instan, seperti polaroid di dalam tampilannya. Sedangkan untuk kata "Gram" berasal dari kata "Telegram", dimana cara kerja telegram sendiri adalah untuk mengirimkan informasi kepada orang lain dengan cepat. Sama halnya dengan Instagram yang dapat mengunggah foto dengan menggunakan jaringan internet, sehingga informasi yang ingin disampaikan dapat diterima dengan cepat. Oleh karena itulah Instagram berasal dari "InstanTelegram" (Saputra, 2013)

Pada 2015 yang lalu Instagram memiliki 400 juta pengguna di seluruh dunia. Pada hari pertama dirilis, menurut pendiri Instagram, Kevin Systrom, layanan tersebut berhasil 
memikat 25 ribu pendaftar. (Librianty, 2015). Selanjutnya, Asosiasi Penyelenggara Jasa Internet Indonesia (APJII) mengumumkan jumlah pengguna internet Indonesia pada tahun 2016 yang mencapai 132,7 juta. Pada survei terakhir yang diungkap APJII tahun 2014, ada pertumbuhan penetrasi pengguna internet 51,8 persen dari 88 juta menjadi 132,7 juta pada saat ini. Dari data tersebut Konten Media Sosial yang Sering Dikunjungi Facebook dengan 54 persen (71,6 juta), Instagram 15 persen (19,9 juta), dan YouTube 11 persen (14,5 persen), (Lismartini, 2016)

Melalui laman beritatagar.id, berikut temuan yang dilakukan oleh TNS, sebuah lembaga riset dari Inggris, mengenai studi "Pengguna Instagram di Indonesia":

- Pengguna Instagram di Indonesia 59\% adalah anak muda usia 18-24 tahun yang terdidik dan mapan.

- $88 \%$ pengguna menggunakan filter dan 97\% menggunakan fitur search untuk mencari informasi yang lebih spesifik.

- 97\% menuliskan komentar pada postingan dan menandai (mention) teman-teman mereka yang mendorong proses pencarian di Instagram.

- $85 \%$ pengguna di Indonesia juga memposting di media sosial lainnya langsung dari Instagram (cross posting).

- Mode dan teknologi menjadi produk yang paling populer di antara para pengguna Instagram di Indonesia.

- $49 \%$ juga membeli produk dari penjual/jenama (brand) yang mereka ikuti (follow).
- Masyarakat Indonesia menggunakan Instagram untuk mencari inspirasi, membagi pengalaman saat bepergian, dan mencari informasi dan tren terbaru.

- Kategori konten yang paling banyak dibagikan di Instagram (berlaku untuk Instagram dan Facebook):

1. Swafoto

2. Makanan yang dimakan

3. Barang yang dibeli

4. Barang yang mau dijual

5. Foto atau video dari keluarga

6. Peristiwa khusus

7. Binatang peliharaan

8. Alam terbuka

9. Tempat-tempat yang pernah dikunjungi

10. Foto atau video dari perjalanan

11. Kutipan atau meme

12. Foto atau video yang ditemukan secara daring (Edwin, 2016)

\section{KUASA DALAM GALERI FOTO (ONLINE)}

Menarik memperhatikan data temuan TNS, bahwa 97\% (pengguna Instagram di Indonesia) menuliskan komentar pada postingan dan menandai (mention) temanteman mereka yang mendorong proses pencarian di Instagram. Peluang untuk membuat sebuah postingan menjadi viral pun terbuka lebar. Konsep desa global yang pernah diutarakan oleh Mc Luhan bisa kita liat melalui fenomena ini. Siapapun bisa membicarakan apa dan dimana, tanpa tersekat persoalan geografis. Atas gejala semacam ini, maka dimungkinkan ruang 
komentar dapat berfungsi sebagai mode pengawasan dan pendisiplinan.

Dalam Surveiller et Punir (1975), disiplin dianalisa sebagai satu dari teknologi kekuasaan masyarakat modern, sebagai "kekuasaan norma". Disiplin harus dibedakan dari norma. Norma adalah aturan yang menyatakan nilai bersama yang dihasilkan melalui mekanisme acuan diri dan kelompok. Norma memungkinkan untuk perbandingan dan individualisasi. Sedangkan sasaran disiplin adalah tubuh: disiplin mengoreksi dan mendidik. Ini membutuhkan perbandingan dan individualisasi (Haryatmoko, 2016: 21). Tubuh yang termediakan secara visual melalui lensa kamera nyatanya bukanlah tubuh yang bebas nilai. Di depan lensa kamera objek foto membentuk pose, menjadi diri yang lain yang dikosntruksi melalui lensa kamera. Lantas, dengan hadirnya sosial media, foto-foto tersebut mampu diakses dan "diawasi" oleh siapapun.

Konsep pemikiran Michel Foucault perihal pendisiplinan hadir dalam kehidupan masyarakat, melalui model-model pengawasan, atau dikenal sebagai panoptikon. Sistem Panoptikon bekerja selalu mengawasi dan memantau perilaku kehidupan. Dengan adanya sistem ini, diharapkan menjadi model pengawasan yang "melahirkan" pendisiplinan diri. Teknikteknik pendisiplinan muncul di berbagai bidang dan ruang. Foucault mencontohkan mengenai pendisiplinan di Sekolah, Penjara, Rumah Sakit, dan Rumah Sakit Jiwa. Teknikteknik ini memproduksi apa yang disebut Foucault dengan 'tubuh patuh' yang diikat, digunakan, ditransformasikan dan diperbaiki (Foucault, 1977:198, dalam Barker, 2009:84).
Panoptikon di "adopsi” oleh Foucault dari konsep arsitektur penjara yang dikemukakan oleh Jeremy Bentham (1975). Konsep panoptikon untuk mengawasi (-opticon) semua (pan-) tahanan yang terdiri dari lapangan terbuka dengan menara di tengahnya yang bisa digunakan untuk melihat ke seluruh bangunan dan sel, dengan jendela yang mengarah ke menara itu. Penghuni sel terlihat oleh mata sipir di menara itu, namun dia tidak terlihat oleh para penghuni. Sel menjadi 'teater kecil dimana masing-masing actor sendiri, terindividualkan secara sempurna dan terus menerus tak tampak (Foucault, 1977:200, dalam Barker, 2009:85)

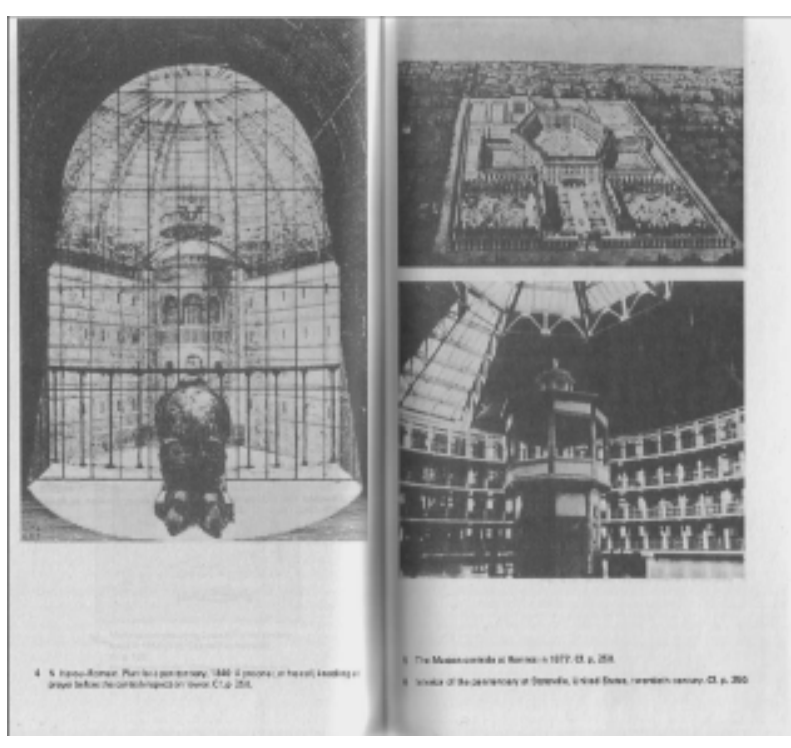

\section{Gambar 1}

Sumber: Foucault, 1995: 169

Penekanan Foucault atas interpretasi yang dilakukan terhadap konsep Bentham terletak pada "kekuasaan". Sebagai konsep kekuasaan, panoptikon bersifat visible dan invariable, dalam arti bahwa visible: orang yang diawasi secara jelas melihat bayangan menara pengawas, sedangkan invariable: orang yang diawasi tidak pernah mengetahui bahwa dirinya diperhatikan tetapi yakin 
bahwa dia selalu diawasi (Indraningsih, 2010). Konsep panoptikan terus berkembag ke arah model pengawasan dan pendisplinan masyarakat dalam berbagai bidang dan ruang. Jika pada awalnya model-model ini diberlakukan dalam penjara, pabrik, sekolah, barak militer atau rumah sakit jiwa, maka di masa sekarang model pendisplinan diri muncul dalam wilayah yang lebih luas. Ketika citraan mampu memberikan gambaran mengenai relasi dan kuasa sosial, maka ruang-ruang sosial, termasuk media sosial bisa melahirkan efek-efek panoptik.

Relasi kuasa yang hadir dalam ruang siber tak bisa dilepaskan dari praktik-praktik pengawasan. Dalam sosial media (instagram) Foto-foto yang diunggah dan terjajar sesuai penanggalan menjadi semacam galeri (online) dan menjadi objek yang terkontrol, baik terkontrol secara online maupun offline. Bourdieu dalam "Photography: A. Middlebrow Art. Cambridge, Polity (1990), seperti dikutip oleh Jenkins (2004:199-200) pernah mencatat perihal "galeri" dan fotografi: bahwa fotografi sebagai praksis atau sebagai karya budaya tampak menjadi sarana pemahaman, dalam ekspresi paling autentik, atas estetika (dan etika) kelompok atau kelas berbeda dan khususnya "estetika" populer yang dapat dimanisfestasikan di dalamnya. Baginya fotografi berfungsi untuk mengungkapkan hubungan ekuivokal antara kelompok. Bourdieu pernah mencoba melakukan analisis atas beberapa pengguna kamera; orang desa, pekerja pabrik dan yang terakhir adalah kelompok fotografi di Lille, dari hasil analisisnya menunjukan bahwa determinisme kelas- melalui mediasi "simbolisme kelompok dan praksis individu-mengkonstruksikan apa yang layak difoto, subjek apa saja yang layak diterima.

Mode pengawasan yang diperantarai oleh lensa kamera pernah disinggung oleh Mrazek dalam Engineers of Happy Land; Perkembangan Teknologi dan Nasionalisme di sebuah Koloni, ia berujar bahwa "dua mata sering tidak cukup untuk mengawasi mereka", (2006: 145). Atas pendapat ini, dapat kita tafsir bahwa fotografi, bukan hanya berfungsi secara teknis sebagai medium dokumentasi, namun juga bisa berfunsgi sebagai "pengawasan", dengan kata lain: kontrol sosial hadir di dalamnya.

\section{Amarilys dan Lensa Panoptik}

Di penghujung 2015 halaman rumah Sukadi, 43 tahun, Dusun Ngasemayu RT 13 RW 04, Salam, Patuk, Gunungkidul mendadak ramai. Pasalnya, tanaman Bunga Amarilys yang ia budidayakan di halaman rumahnya berhasil menarik banyak perhatian masyarakat, terlebih lagi setelah hamparan Amarilysnya muncul di media sosial. Masyarakat sekitar mengenal bunga ini sebagai bunga Brambang Mas atau Bunga Desember, karena mekarnya setiap setahun sekali pada periode November-Desember. Bunga ini dikenal dengan nama Latin Hippeastrum, nama familinya Amaryllidaceae. Nama Hippeastrum lebih dikenal di luar negeri, sedangkan di Indonesia lebih familier bunga Amarilys atau bunga Lily. Total terdapat 60 genus dan 800 spesies bunga ini di seluruh dunia. Warna bunga Hippeastrum sangat menarik yaitu warna merah, putih, merah muda, orange, dan krem. Serta bercorak garis-garis merah muda di atas warna putih, ada juga yang bercorak seperti batik, dan ada juga yang berwarna 
ganda karena hasil persilangan. Tinggi tanaman ini sekitar $60 \mathrm{~cm}$ bahkan jika dibiarkan di alam liar bisa sampai $80 \mathrm{~cm}$. Diameter umbi 5-10 cm. Dari umbi ini akan muncul 1-2 batang Amarilis yang bisa menyokong 2-12 kuntum Amarilis. (Karis, 2015).

Atas pesona Amarilys inilah yang membuat pengunjung senang berfoto dan mengunggah di media sosial. Sepakat dengan apa yang di utarakan oleh Tubagus Savarajati (2013) bahwa "Memotret adalah ekspresi gaya hidup urban: (seakan) upaya mengada”. Ramainya masayarakt yang mengunjungi kebun Amarilys salah satu faktornya adalah keinginan untuk eksis berfoto. Akibatnya, setelah termediatisasi ke dalam media sosial Instagram, jumlah pengunjungpun meningkat dan perbincangan mengenai kebun milik Sukadi ini pun kian ramai.

Realitas dalam ruang siber menggambarkan mengenai keberadaan serta keinginan seseorang untuk mengada. Mengenai konstruksi identitas yang diperantarai oleh fitur "suka", "komentar", dan "bagikan" yang selanjutnya menjadi parameter tingkat eksistensi pengguna. Melalui media sosial, tiap pengguna dari wilayah manapun, bahkan tanpa saling mengenalpun bisa saling berinteraksi. Interaksi dalam ruang siber menjadi lebih bebas, tidak seperti dalam interaksi "offline" dengan pola komunikasi -saling tatap- antara dua individu yang justru dianggap lebih kompleks dengan melibatkan lingkungan di sekitar pengguna, gesture, juga ekspresi wajah, dalam ruang siber (online) akan semakin minim kita jumpai.

Menyitir kata Roland Barthes dalam Camera Lucida Reflection on Photography
(1982) ketika dirinya berhadapan dengan lensa kamera, ia telah membuat tubuh lain bagi dirinya. Antara diri dan citra diri menjadi terpisahkan, menjadi yang lain atas tubuhnya sendiri. Ia menderita ketidakotentikan. Dan dapat dikatakan bahwa dengan berpose di depan kamera, dengan menyeleksi objek-objek yang berada di sekitar, kita tengah menciptakan identitas baru akan diri kita. Keinginan mengada hadir dalam situasi seperti ini. Lebih lanjut, dalam konteks, bermedia sosial keinginan mengada tersebut semakin berjejaring ketika ada respon yang didapat dari pengguna lain.

Dalam foto-foto yang terkumpul dalam satuan tanda pagar (tagar) \#saveamarilys kita bisa melihat aneka foto yang diunggah penggunanya. Tagar menjadi pengacu atas foto-foto serupa, baik secara kejadian maupun serupa dari sisi konten dan tujuannya. Ketika sebuah foto masuk dalam sebuah himpunan tagar (\#) maka foto tersebut menjadi objek terkontrol dan diawasi, terlebih lagi jika menyampai titik puncak atau trending topic. Media sosial bukan hanya membangun hubungan antara penggunanya namun juga membangun hubungan antar pengguna itu sendiri dengan teknologi yang dipegangnya. Misalnya seperti pemilihan filter dan cara pengambilan (dalam format swafoto), yang di dalamnya memberikan pesan mengenai aktualiasisai sebagai proyek diri. Dengan berswafoto kita memberikan penguasaan visual atas diri sendiri dan hal tersebut menjadi cara kerja kultural dalam penegasan politik visual dengan tujuan mengarah pada gaya hidup.

Teknologi fotografi memang terlahirkan untuk memburu objektivitas, karena kemampuannya untuk 
menggambarkan kembali realitas visual dengan tingkat presisi yang tinggi (Ajidarma, 2016:1). Penggambaran kembali realitas inilah yang akan semakin berjejaring efeknya, dalam bentuk meme, misalnya. Tanda pagar dalam media sosial instagram berfungsi untuk mengarahkan pengguna dalam melakukan pengumpulan sekaligus mempermudah dalam pencarian konten (foto) sejenis. Melalui tagar \#saveamarilys kita bisa mendapati seribu lebih postingan mengenai fenomena rusaknya bunga Amarilys di Patuk, Gunung Kidul. Berikut beberapa foto yang terhimpun dalam "pengawasan" tagar \#saveamarilys.

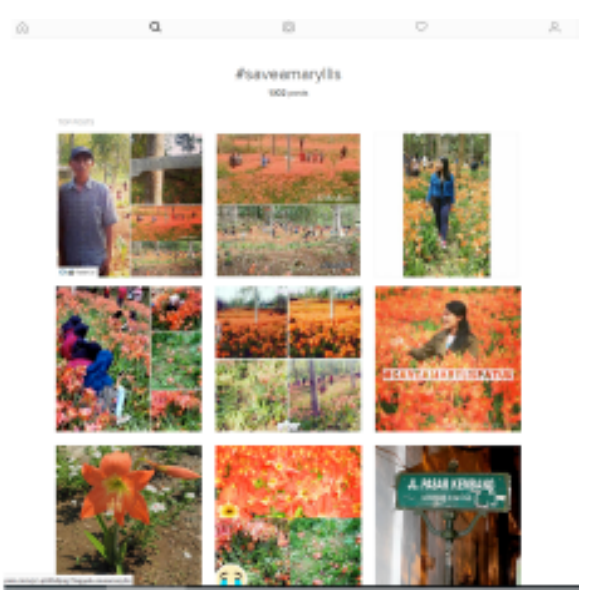

Gambar 2 Kumpulan foto yang diunggah dengan bertagar \#saveamaryllis

Sumber: https://www.instagram.com/p/qUJ22LFOi/?tagged=saveamaryllis,

Mengutip Tubagus Savarajati: Pengalaman saya, atau siapapun, saat melihat dan tersentak oleh visualitas terhenti dari sebuah foto adalah kesadaran fenomenologis. Orang tercekat oleh suatu penampakan yang diyakini benar adanya meskipun ia tidak secara langsung berada di dalam momen foto itu (Svarajati, 2013:40). Menyaksikan foto bukanlah kegiatan yang bebas nilai, di dalamnya muncul ragam wacana. Menyoal hal paling sederhana, hingga wacana yang paling kompleks. Kehendak mengada dalam sosial media muncul melalui postingan dan diperkuat melalui keterangan foto. Semakin banyak respon ("suka", "komentar", "bagikan") yang didapat maka daya visual akan semakin bertambah. Semakin kuat daya yang dihasilkan, maka pengawasanpun akan semakin kuat pula. Dan semakin banyak pengguna yang terlibat, wacana yang munculpun akan semakin kuat.

Kemampuan fotografi sebagai layar panoptikon, saya sebut "layar" karena melalui fotografi kita menyaksikan sebuah realitas yang terhampar dalam sebuah bidang, seperti sedang menyaksikan sebuah tontonan. Foto yang diposting disertai teks yang akan mengarahkan pada penafsiran. Teks menjadi representasi pengguna lain dalam merespon foto yang diposting, dapat kita lihat pada postingan@muhaiminah_jalal, melalui postingannya (gb.3.) ia menuliskan "sedih banget lihatnya..taman bunga amarilys yg awalnya indah bgt jadi rusak karna di injak2 kaki2 manusia yang tak bertanggung jawab. Mau exis tp ngrusak :) \#amarilys \#jogja \#gunungkidul \#saveamariliys

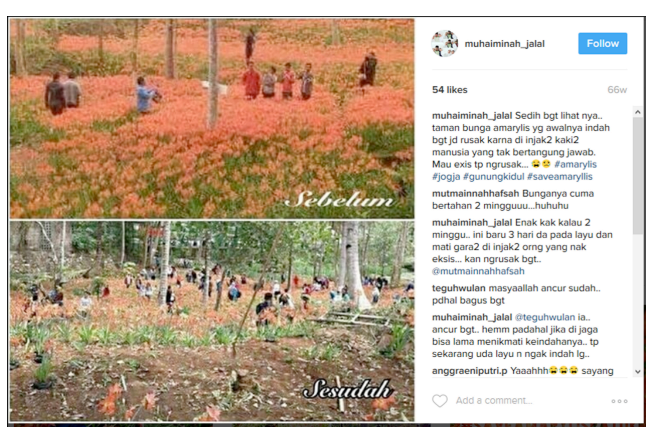

Gambar 3 Salah satu foto yang diunggah oleh netizen menunjukan kondisi kebun bunga Amarillys Sumber: https://www.instagram.com/p/qUJ22LFOi/?tagged=saveamaryllis, 
Ramainya perbincangan \#Saveamarilys di Instagram mengarah pada beberapa akun pengguna yang di dalamnya berisi pose di hamparan kebun bunga. Dari banyaknya postingan bertagar \#Saveamarilys, saya coba ambil salah satu sebagai sampel, yakni foto seorang pengguna Instagram dengan akun @hestisundari_. Atas postingan fotonya di kebun Amarylis membuat dirinya dibully oleh netizen. Pengawasan mengacu, salah satunya pada pose foto, respon yang didapat bukan saja berupa komentar namun juga meme-meme mengenai dirinya. Praktik panoptikon berhubungan erat dengan praktik kuasa. Kuasa tidak dapat dilokalisir akan tetapi terdapat dimana-mana. Selama ini, kuasa dikaitkan dengan orang atau lembaga tertentu, khususnya aparat negara. Foucault menyatakan bahwa kuasa itu tidak hanya terkait dengan lembaga tertentu, kuasa justru terdapat dimana-mana. Dimana-mana kita temukan aturan-aturan, sistem regulasi yang menentukan bagaimana kuasa bekerja (pada hubungan sosial, seksualitas, media komunikasi, pendidikan, dan pengetahuan) (Lubis, 2014:178).

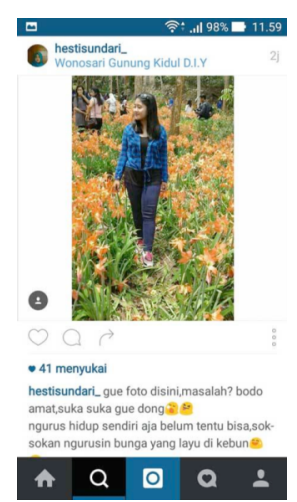

Gambar 4 Salah satu foto pengguna instagram yang menjadi perbincangan netizen.

\section{Sumber:}

http://warungkopi.okezone.com/thread/450966/perus ak-bunga-amarylis- akhirnya-minta-maaf-di-akuninstagramnya

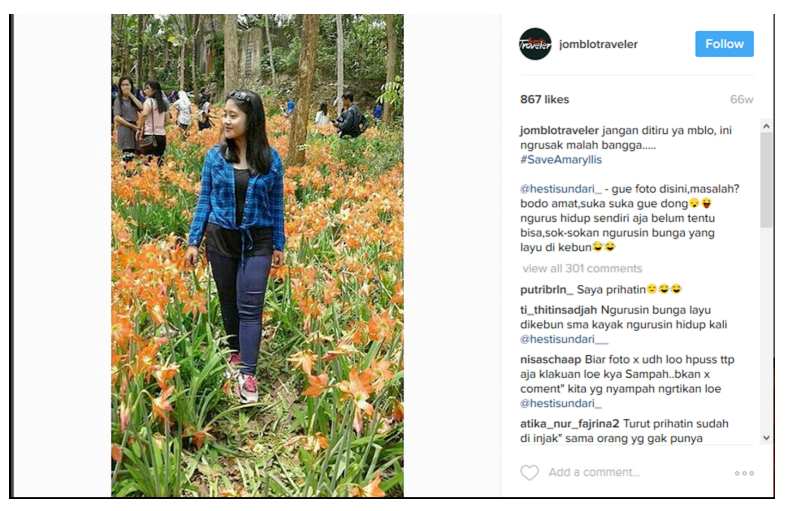

Gambar 5 Respon atas perilaku netizen Sumber: https://www.instagram.com/p/qUJ22LFOi/?tagged=saveamaryllis,

Pada gb.4.,melalui akun Instagramnya ia menuliskan, " gue foto disini, masalah? Bodo amat, suka-suka gue dong. Ngurus hidup sendiri aja belum tentu bisa, sok-sokan ngurusin bunga yang layu di kebun". Dalam hal ini teks mampu mengaitkan pada materi visual yang nampak, sehingga penafsiran turut ditentukan melalui teks yang ada. Seperti yang diutarakan oleh Stuart Hall dalam The Determinations of News Photographs (1973) mengenai "Preferred Reading”, bagaimana kata-kata memiliki daya untuk membimbing pemaknaan terhadap karya foto. Foto tersebut kemudian mendapat respon dari warga siber yang lain, fotonya menjadi menyebar dan pengawasan hadir, salah satunya terepresentasi melalui tagar \#Saveamarilys. "Jangan ditiru ya, mblo, ini ngrusak malah bangga....\#Saveamarilys., tulis @jomblotraveler dalam akun instagramnya.

Seperti telah disampaikan sebelumnya, bahwa panoptikon bekerja selalu mengawasi dan memantau perilaku kehidupan. Dengan adanya sistem ini, diharapkan menjadi model pengawasan yang "melahirkan" pendisiplinan diri. Instrumen pengawasan ini terlihat dari komentar dan juga tingginya respon dari 
pengguna yang lain. Meningkatnya daya pengawasan, salah satu indikatornya juga bisa diukur melalui lonjakan jumlah pengikut di akun instagramnya. Banyak yang memperbincangkan foto yang ia posting, membuat si pengguna menjadi merasa kian "terkontrol" dan sadar, lantas melalui akun pribadinya ia menyampaikan permintaan maaf, dengan keterangan foto sebagai berikut:

"Minta maaf untuk semua dan seluruh pihak yang merasa dirugikan, tujuan saya ke sini cuma main, memang saya akui salah, nginjek sebagian kecil bunga itu, tapi banyak juga yang kesana bukan cuma saya, dan pas saya kesana, juga sudah banyak bunga-bunga yang terinjak dan layu, jadi jangan salah paham dulu dengan foto-foto saya yang kemarin. Sekali lagi, saya pemilik akun ini meminta maaf sebesar-besarnya atas tulisan dan tingkah saya yang tidak mengenakan hati. Terimakasih"

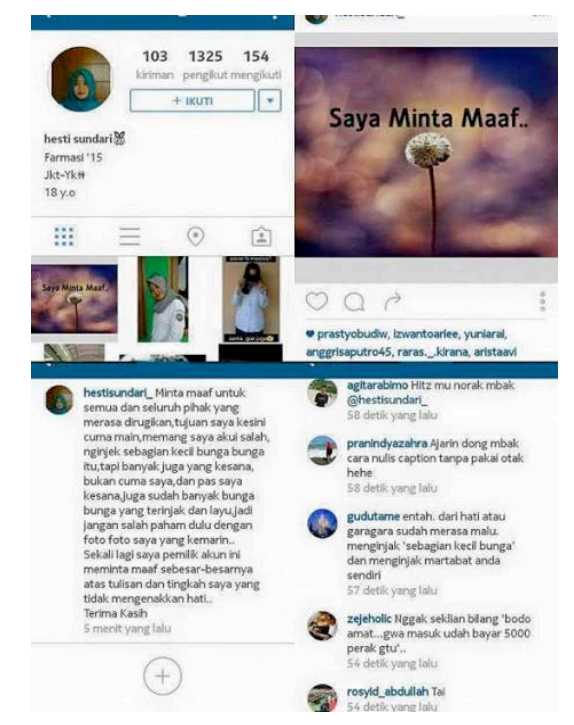

Gambar 6 Permintaan maaf salah satu pengguna, setelah foto yang diunggah mendapat respon dari para netizen

Sumber: Laksana, 2015
Dalam fenomena mengenai bunga Amarilys kita bisa melihat bagaimana ruang virtual yang begitu cair. Kuasa, seperti kata Foucault tidak dimiliki, namun sebagai sebuah strategi, kuasa berlangsung dimanamana. Di mana terdapat aturan, sistem regulasi maka di situlah kuasa bekerja. Pasca munculnya foto-foto taman bunga Amarilys yang rusak, dan komentar yang hadirpun beragam. Selanjutnya, meme-meme yang berhubungan dengan fenomena tersebut mulai bermunculan. Meme menjadi semacam komunikasi sekaligus dokumentasi peristiwa yang dibingkai secara visual. Lebih jauh, meme bukan sekadar lelucon, namun ada resistensi yang bekerja di dalamnya. Dengan meminjam materi visual yang asli, dalam artian materi visual yang berhubungan langsung dengan momen yang sedang ramai dibicarakan, maka meme menjadi keberlanjutan dari hadirnya pengawasan tersebut. Ada kritik sosial, juga pesan-pesan yang parodis di dalamnya. Berikut beberapa contoh meme yang muncul.

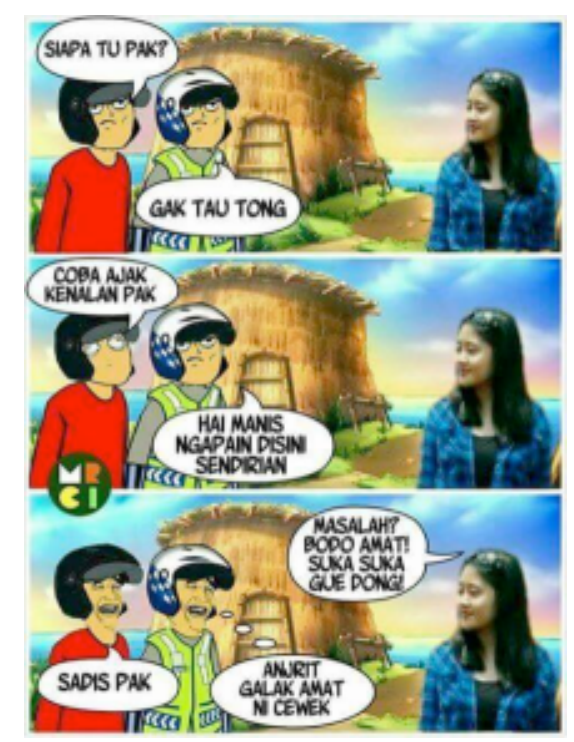



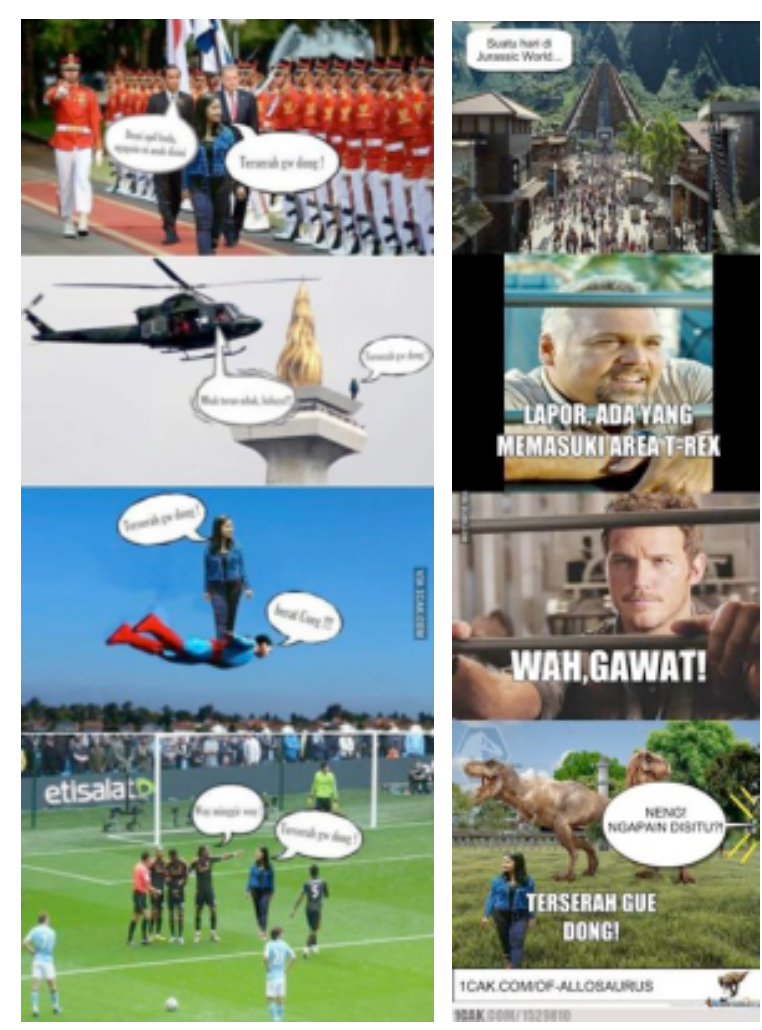

Gambar 7 Kumpulan meme terkait fenomena rusaknya kebun bunga Amarillys

Sumber: Ayu, 2015

Meme terbangun atas dua hal yang saling bertaut: teks dan visual (bisa berupa foto, maupun ilustrasi). Aspek visual diambil dari fenomena-fenomena yang sedang ramai diperbincangkan kemudian dibubuhi teks. Dan teks yang dihadirkan bisa saja berasal dari fenomena yang sama dengan visualnya, bisa juga berbeda. Bisa juga saling mengkombinasikan antara materi visual yang dirasa memiliki daya tarik tersendiri. Keterikatan terbangun karena ada kesamaan kode. Pemahaman akan meme sejatinya bukan sesuatu yang alamiah terjadi. Sebagai sebuah strategi visual, meme bukan saja lelucon namun di dalamnya memuat konten visual yang parodis atas efek viralnya sebuah postingan di media sosial. Media sosial mampu membangun layar panoptik yang tajam, siapapun terlibat dalam pendisiplinan tubuh.

Ramainya fenomena foto kunjungan dan rusaknya Amarilys di media sosial mampu melahirkan kontrol, bukan saja melahirkan kesadaran akan berwisata yang tertib dan bijak, namun pendisplinan dan penataan lingkungan kebun Amarilys sebagai objek wisata mulai diwacanakan oleh Pemerintah setempat. Seperti dikutip melalui laman Kompas.com bertanggal Senin, 14 Desember 2015

"Kita sudah berkoordinasi dengan
bupati, sekda, dan UGM untuk rencana
pembangunan taman Amaryllis," ujar
Camat Patuk Gunung Kidul, Haryo
Ambar Suwardi, Senin (14/12/2015).

Ambar menuturkan, saat ini UGM dan beberapa ahli telah membuat desain taman. Nantinya akan ada berbagai bunga untuk memperindah taman. Namun, saat ini baru akan dikembangkan satu jenis, yakni Amaryllis.

"Tentu disediakan spot selfie bagi wisatawan. Jadi bisa berfoto dengan latar belakang bunga tanpa harus menginjak dan merusaknya," tandasnya. (Kusuma, 2015)

\section{PENUTUP}

Kekuasan bukan dimiliki namun distrategikan, begitu kata Foucault. Dalam media sosial yang serba cair, siapapun bisa menjadi apa sesuai dengan yang diinginkan. Konstruksi diri yang modern, yang bergayahidup menjadi isu yang kerap dimunculkan. 
Pun dengan fenomena bunga Amarilys. Dalam hal ini, media sosial bukan hanya berfungsi sebagai ruang sosialisasi dan interaksi, namun juga berfungsi sebagai layar panoptikon. Sistem Panoptikon bekerja selalu mengawasi dan memantau perilaku kehidupan penggunanya. Fitur-fitur yang dihadirkan seperti "suka", "komentar", dan bagikan" menjadi indikasi parameter seberapa kuat pengawasan itu bekerja, dan dampak dari pengawasan ini adalah kontrol sosial dan pendisiplinan.

\section{DAFTAR PUSTAKA}

[1] Ajidarma, Seno Gumira. 2016. Kisah Mata Fotografi antara Dua Subjek: Perbincangan Tentang Ada (edisi 2). Yogyakarta: Galangpress

[2] Barker, Chris. 2009. Cultural Studies Teori dan Praktik. Yogyakarta: Kreasi Wacana.

[3] Barthes, Roland. 1982. Camera Lucida Reflection on Photography. Translated by Richard Howard. New York: Hill and Wang.

[4] Foucault, Michel. 1995. Discipline and Punish The Birth of The Prison.

[5] Haryatmoko. 2016. Membongkar Rezim Kepastian; Pemikiran Kritis PostStrukturalisme. Yogyakarta: Kanisius

[6] Ibrahim, Idi Subandy. 2011. Kritik Budaya Komunikasi; Budaya, Media, dan Gaya Hidup dalam Proses Demokratisasi di Indonesia. Yogyakarta: Jalasutra

[7] Jenkins, Richard. 2004. Membaca Pikiran Pierre Bourdieu (terj.). Yogyakarta: Kreasi Wacana

[8] Indraningsih. 2010. Internalisasi Disiplin dalam Penggunaan Internet di Kalangan Pelajar di Indonesia: Sebuah Kajian Filosofis Pemikiran Michel Foucault. Di sampaikan pada persidangan antar bangsa sains dan Teknologi ALam
Melayu (SALAM 1) pada tanggal 15-17 Desember 2010 di Pusat Konvensyen Kuala Lumpur.

[9] Lubis, Akhyar Yusuf. 2014. Teori dan Metodologi Ilmu Pengetahuan Sosial Budaya Kontemporer. Jakarta: Rajawali Pers.

[10] Mrazek, Rudolf. 2006. Engineers of Happy Land Perkembangan Teknologi dan Nasionalisme di sebuah Koloni. Jakarta: Yayasan Obor Indonesia.

[11] Nasrullah, Rulli. 2014. Teori dan Riset Media Siber. Jakarta: Kencana.

[12] 2015. Media

Sosial Perspektif Komunikasi, Budaya, dan Sosioteknologi. Bandung: Simbiosa Rekatama Media

[13] Piliang, Yasraf Amir. 2006. "Imagologi dan Gaya Hidup" dalam Resistensi Gaya Hidup: Teori dan Realitas. Yogyakarta: Jalasutra

[14] Setiawan, Rudi dan Mardohar Batu Bornok. 2015. Estetika Fotografi. Lembaga Penelitian dan Pengabdian kepada Masyarakat Universitas Katolik Parahyangan: Bandung

[15] Sunjayadi, Achmad. 2008. Mengabadikan Estetika Fotografi dalam Promosi Pariwisata Kolonial di HindiaBelanda. Jurnal Wacana, Vol. 10. No. 2, Oktober 2008 (301-316). Jakarta: Universitas Indonesia

[16] Strassler, Karen. 2010. Refracted Vision: Popular Photography and National Modernity in Java. London: Duke University Press.

[17] Svarajati, Tubagus, 2013. Photagogos Terang Gelap Fotografi Indonesia. Semarang: Suka Buku

\section{Sumber Internet}

[1] Ayu, Noviana. 2015. Kumpulan Meme Hesti Sundari Kebun Bunga Amarilys. https://ngonoo.com/2015/12/132433/ku mpulan-meme-hesti-sundari-kebun- 
bunga-amarylis/. Diakses pada 13 September 2016, pukul 13.04

[2] Edwin, Yoseph. 2016. Instagram Beberkan Fakta-Fakta Pengguna di Indonesia.

https://beritagar.id/artikel/sainstekno/instagram-beberkan-fakta-faktapengguna-di-indonesia. diakses pada 12 Maret 2016. Pukul 15.05

[3] Karis. 2015. Mengenal Lebih Dekat Bunga Amarylis, Bunga yang tengah Ngetop Gara-gara Kelakuan ABG Alay. https://rideralam.com/2015/11/29/meng enal-lebih-dekat-bunga-amarylis-bungayang-tengah-ngetop-gara-gara-kelakuanabg-alay/ diakses pada 4 September 2016 Pukul 12.38.

[4] Kusuma, Wijaya. 2015. Pengembangan Taman Bunga Amaryllis Rampung pada 2016.

http://regional.kompas.com/read/2015/1 2/14/14385561/Pengembangan.Taman.B unga.Amaryllis.Rampung.pada.2016.

diakses pada 21 September 2016. Pukul 21.00

[5] Laksana, Nur Chandra. 2015. Di Bully Netizen Perusak Taman Amarilys Minta Maaf. http://www.money.id/digital/dibully-netizen-perusak-taman-amaryllisminta-maaf-151201g.html. Di akses pada 13 September 2016. Pukul 12.30

[6] Librianty, Andina. 2015. Melongok Sejarah Instagram 5 Tahun Lalu. http://tekno.liputan6.com/read/2335921/ melongok-sejarah-instagram-5-tahunlalu diakses pada 3 Mei 2016. Pukul 20.10

[7] Lismartini, Endah dan Agus Tri Haryanto. 2016. Pengguna Internet Indonesia Lebih Banyak Akses Medsos. http://teknologi.news.viva.co.id/news/rea $\mathrm{d} / 838870$-pengguna-internet-indonesialebih-banyak-akses-medsos. Senin, 24 Oktober 2016 | 22:51 WIB. Diakses pada 26 Oktober 2016. Pukul 20.30.
[8] Saputra, Irwan. 2013. Sejarah Aplikasi Instagram. http://www.netterku.com/2013/03/sejara h- aplikasi-instagram.html diakses pada 3 Maret 2016, Pukul 19.50.

[9] http://warungkopi.okezone.com/thread/ 450966/perusak-bunga-amarylisakhirnya-minta-maaf-di-akuninstagramnya, diakses pada 10 Maret 2016. Pukul 11.55.

[10] https://www.instagram.com/p/qUJ22LFOi/?tagged=saveamaryllis, diakses pada 22 Oktober 2016, Pukul 19. 45. 